\title{
MENENTUKAN AWAL MUSIM TANAM DAN OPTIMASI PEMAKAIAN AIR DAN LAHAN DAERAH IRIGASI BATANG LAMPASI KABUPATEN LIMAPULUH KOTA DAN KOTA PAYAKUMPUH
}

\author{
Mas Mera ${ }^{1}$ dan Hendra ${ }^{2}$
}

\begin{abstract}
ABSTRAK
Daerah Irigasi Batang Lampasi berada di Kabupaten Limapuluh Kota dan Kota Payakumbuh, sedangkan weirnya terdapat di Limapuluh Kota. Sebagian areal irigasi Batang Lampasi ini tidak menghasilkan padi maupun palawija, karena pengaturan air untuk musim tanam tidak berpedoman pada volume andalan sungai. Dari hasil pengukuran, efisiensi saluran primer, sekunder dan tersier Daerah Irigasi Batang Lampasi diperkirakan sebesar $64 \%$. Berdasarkan keadaan eksisting yang telah dilakukan petani, maka perlu dilakukan pengaturan pola tanam dengan menentukan awal musim tanam yang tepat agar penggunaan lahan dapat dioptimalkan. Berdasarkan volume andalan diperoleh volume air terbesar di Januari II dan Januari I, sehingga awal musim tanam dipilih pada Januari I dan Januari II. Dalam studi ini ditetapkan tiga alternatif pola tanam yang dipilih yaitu: padi-padi (kondisi eksisting); padi-padi-padi; dan padi-padi-palawija. Optimasi ketiga pola tanam tadi menggunakan metode goal programming, dengan fungsi sasarannya adalah memaksimalkan luas lahan dan meminimalkan kebutuhan air, dan fungsi kendalanya adalah luas areal irigasi dan volume andalan sungai. Hasil optimasi dengan metode Goal Programming diperoleh pola tanam yang menghasilkan luas lahan optimal yaitu pola tanam padi (1319 ha) - padi (848 ha) - palawija (1500 ha) dari luas areal $1500 \mathrm{Ha}$.
\end{abstract}

Kata kunci: volume andalan, musim tanam, kebutuhan air, pola tanam, goal programming.

\section{PENDAHUluaN}

Untuk meningkatkan produksi dan menunjang produktivitas pangan diperlukan ketersediaan air yang cukup, agar pola tanam dapat dilaksanakan secara optimal. Konsekuensinya adalah penggunaan air irigasi selayaknya dilakukan secara efektif dan efisien dengan cara menentukan awal musim tanam yang tepat. Untuk menentukan jenis tanaman yang akan di tanam pada musim tertentu kita harus memperhatikan ketersediaan air. Kegiatan penyuluhan tentang pengaturan pola tanam hendaknya dapat disesuaikan dengan ketersediaan air yang ada, agar pemakaian air bisa maksimal.

Ketersediaan air yang sedikit dan tidak sesuai dengan luas lahan yang ada perlu dilakukan optimasi, supaya hasil yang didapat bisa maksimal dalam satu tahun. Peneliti terdahulu tentang masalah ini di antaranya adalah Pamuji (2007), Wardhani (2008), Aji (2009), Mahmud (2009), Prasetijo (2011), Taufan dkk (2013) dan Talitha (2013). Pamuji (2007) melakukan optimasi pemakaian air dan lahan di Daerah Irigasi Banjaran Kabupaten Banyumas Jawa Tengah. Hasilnya adalah tahap I pada Oktober I (791,15 ha), tahap II pada Oktober II (2150,74 ha), tahap III pada Nopember I

\footnotetext{
${ }^{1}$ Dosen Jurusan Teknik Sipil Fakultas Teknik Universitas Andalas, masmera@ft.unand.ac.id

${ }^{2}$ Mahasiswa Jurusan Teknik Sipil Fakultas Teknik Universitas Andalas, hendra.73hh@gmail.com
} 
(2150,74 ha), tahap IV pada Nopember II (2658,82 ha) tahap V pada Desember I ( 3573,15 ha) dan tahap VI pada Desember II (3573,15 ha). Wardhani (2008) melakukan optimasi pemakaian air irigasi Tajum Kabupaten Banyumas. Hasilnya adalah ketersediaan air di Daerah Irigasi Tajum masih mencukupi kebutuhan air irigasi yaitu 3200 ha, dengan musim tanam I dimulai pada pertengahan bulan Oktober secara serentak. Aji (2009) melakukan optimasi penggunaan air pada Daerah Irigasi Mrican Kanan di Kabupaten Kediri Jawa Timur. Hasilnya adalah pola tanam padipalawija-palawija dengan awal tanam bulan Desember I yaitu Rp.50.394.972.530 (eksisting) menjadi Rp.61.691.506.640 (pola tanam baru). Mahmud (2009) melakukan optimasi potensi dan pola pemanfaatan air di Daerah Irigasi Wawatobi Sulawesi Tenggara, dengan melakukan enam alternatif awal tanam yaitu Desember I, Desember II, Januari I, Januari II, Februari I dan Februari II. Hasilnya adalah alternatif ke-tiga, yaitu pada Januari I yang memberikan solusi terbaik. Prasetijo (2011) melakukan optimasi pola tanam untuk memaksimalkan keuntungan petani di Daerah Irigasi Prambatan Kiri Jawa Timur. Hasilnya pola tanam padi/apel-padi/palawija/apel-padi/palawija/apel yang mendapatkan keuntungan paling maksimum. Taufan dkk (2013) melakukan optimasi pola tanam di Daerah Irigasi Konto Surabaya terletak di Kabupaten Jombang dengan menggunakan program linear. Dari beberapa alternatif rencana, diperoleh pola tanam yang memberikan penghasilan terbesar yaitu pola tanam padi-tebu, padi-palawija-tebu, palawija-tebu pada awal tanam Desember 1 dengan penghasilan Rp. 89,590,510,000.00 dan intensitas tanam 248,97 \%. Talitha (2013) melakukan optimasi penggunaan lahan dan air di Daerah Irigasi Kandis Kecamatan Lengayang Kabupaten Pesisir Selatan Sumatera Barat, dengan tiga alternatif pola tanam yaitu padipadi-padi, padi-padi-palawija dan padi-padi/palawija-padi/palawija dengan awal tanam, yaitu Oktober I dan Oktober II. Hasilnya adalah pola tanam padi-padi-palawija dengan awal tanam Oktober II yang memberikan hasil terbesar.

Tujuan penelitian ini adalah mengoptimasikan pemakaian air irigasi Batang Lampasi dengan berbagai pola tanam menggunakan metode goal programming dengan fungsi sasarannya adalah memaksimalkan luas lahan dan, meminimalkan kebutuhan air, dan fungsi kendalanya adalah luas areal irigasi, yang diperhitungkan dalam masalah ini adalah 1500 ha, dan volume andalan sungai.

\section{METODOLOGI, HASIL DAN DISKUSI}

Penelitian ini dimulai dengan melakukan survey ke lapangan dengan mewawancarai penduduk untuk mendapatkan informasi tentang pola tanam yang dilakukan selama ini, tanaman yang ditanami dan keadaan air irigasi. Memeriksa jaringan irigasi untuk mengatahui kondisi eksisting jaringan irigasi, meminta informasi dari juru irigasi tentang luas areal irigasi untuk memperkirakan luas areal Daerah Irigasi Batang Lampasi saat ini dan mengukur debit sesaat untuk menentukan efisiensi jaringan irigasi. Selanjutnya mengumpulkan data curahan hujan yang diperoleh dari Balai PSDA Wilayah Bukittinggi, yaitu data curahan hujan 15-harian pada stasiun curahan hujan Tanjung Pati selama 20 tahun dari tahun 1993 sampai 2012, untuk menentukan hujan andalan dan hujan efektif. Data klimatologi dengan panjang 11 tahun dari tahun 2002 sampai 2012 juga diperoleh dari Balai PSDA Wilayah Bukittinggi, untuk menentukan evapotranspirasi potensial yang dipengaruhi beberapa faktor, seperti intensitas penyinaran matahari, kecepatan angin, temperatur udara, dan tekanan udara. Evapotranspirasi potensial juga menggambarkan energi yang didapatkan dari matahari. Data debit sungai juga diperoleh dari Balai PSDA Wilayah Bukittinggi, yaitu data debit 15-harian Batang Lampasi selama 20 tahun dari tahun 1993 sampai 2012, untuk memperkirakan debit andalan 15-harian dengan tingkat keandalan sebesar 80\%, yaitu debit dengan peluang kejadian $80 \%$ terpenuhi.

\section{2 | JURNAL REKAYASA SIPIL}




\subsection{Efisiensi Saluran}

Mengukur debit sesaat dengan menggunakan current meter untuk menentukan efisiensi saluran irigasi (Tabel 2.1).

Tabel 2.1. Rekapitulasi pengukuran debit Daerah Irigasi Batang Lampasi

\begin{tabular}{|c|c|c|c|c|c|c|c|}
\hline \multirow{3}{*}{ No. } & \multirow{3}{*}{ Nama Saluran } & \multicolumn{2}{|c|}{ Lokasi } & \multirow{2}{*}{$\begin{array}{c}\text { Jarak } \\
\text { Pengukuran }\end{array}$} & \multirow{2}{*}{$\begin{array}{c}\text { Kehilangan } \\
\text { sepanjang daerah }\end{array}$} & \multirow{2}{*}{$\begin{array}{l}\text { Panjang } \\
\text { Saluran }\end{array}$} & \multirow{2}{*}{ Efisiensi } \\
\hline & & $\mathrm{Q}_{\text {hulu }}$ & $\mathrm{Q}_{\text {hilir }}$ & & & & \\
\hline & & $\left(\mathrm{m}^{3} / \mathrm{dt}\right)$ & $\left(\mathrm{m}^{3} / \mathrm{dt}\right)$ & $\left(\mathrm{m}^{\prime}\right)$ & Pengukuran & $\left(\mathrm{m}^{\prime}\right)$ & $(\%)$ \\
\hline 1 & Primer & 1,561 & 1,474 & 100,00 & $8,73 \%$ & 276,70 & $78 \%$ \\
\hline 2 & Sekunder & 1,273 & 1,216 & 700,00 & $5,70 \%$ & $16.378,40$ & $25 \%$ \\
\hline 3 & Tersier & 0,528 & 0,490 & $1.000,00$ & $3,79 \%$ & $3.093,00$ & $89 \%$ \\
\hline & Jumlah & & & & & & $64 \%$ \\
\hline
\end{tabular}

\subsection{Curahan hujan andalan dan hujan efektif}

Panjang data curahan hujan yang digunakan untuk penelitian ini adalah 20 tahun, diperlukan komulatif curahan hujan selama 15 hari yang disebut dengan curahan hujan periode 15-harian. Tinggi curahan hujan periode 15-harian andalan adalah tinggi curahan hujan yang digunakan tanaman untuk mengganti kehilangan air akibat evapotranspirasi, perkolasi, kebutuhan pengolahan tanah dan penyiapan lahan. Tinggi curahan hujan andalan biasanya diperoleh dari tinggi curahan hujan yang memunyai peluang $80 \%$ ada $\left(R_{80}\right)$ untuk tanaman padi dan yang memunyai peluang $50 \%$ ada $\left(R_{50}\right)$ untuk tanaman palawija dengan formula (Chow, 1994).

$$
\begin{aligned}
& \text { Urutan } R_{80}=\frac{n}{5}+1 \\
& \text { Urutan } R_{50}=\frac{n}{2}+1
\end{aligned}
$$

dimana $n$ adalah jumlah data curahan hujan periode 15-harian. Sebagai contoh untuk Januari I, $n=$ 20 maka: urutan $R_{80}=20 / 5+1=5$ dan $R_{50}=20 / 2+1=11$. Ini artinya nilai $R_{80}$ adalah berada pada urutan ke 5 , sehingga $R_{80}=58 \mathrm{~mm}$ dan nilai $R_{50}$ berada di urutan ke 11 , sehingga $R_{50}=97 \mathrm{~mm}$. Demikianlah untuk periode yang lain seperti yang ditampilkan pada Tabel 2.2.

Tabel 2.2. Tinggi curahan hujan andalan (mm)

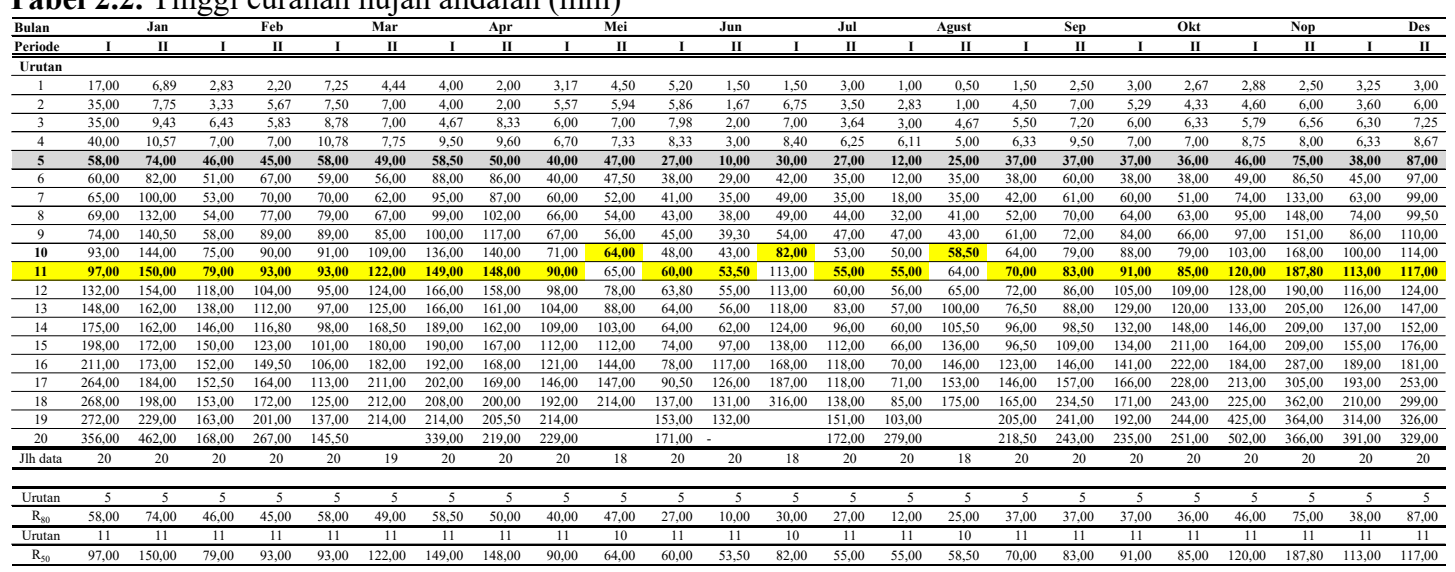

Berdasarkan data curahan hujan di atas, selanjutnya dilakukan perhitungan untuk curahan hujan efektif kebutuhan air tanaman. Untuk irigasi, curahan hujan efektif padi dan palawija diambil $70 \%$ dari curahan hujan andalan dengan periode ulang rencana tertentu yaitu $R_{80}$ untuk padi dan $R_{50}$ untuk palawija dapat dilihat pada Tabel 2.2 atau 2.3. Berdasarkan nilai $R_{80}$ dan $R_{50}$ tersebut, maka 
nilai hujan efektif $R_{e}$ dapat ditentukan, misalnya untuk bulan Januari I ( $t=15$ hari, $R_{80}=58, R_{50}=$ $97 \mathrm{~mm})$, maka :

$$
\begin{aligned}
& R_{\text {epadi }}=\frac{70 \%}{t} \times R_{80}=\frac{0,70}{15} \times 58=2,707 \mathrm{~mm} / \mathrm{hari} \\
& R_{\text {epalawija }}=\frac{70 \%}{t} \times R_{50}=\frac{0,70}{15} \times 97=4,527 \mathrm{~mm} / \mathrm{hari}
\end{aligned}
$$

Jadi hujan efektif untuk padi adalah $2,707 \mathrm{~mm} /$ hari dan untuk palawija adalah $4,527 \mathrm{~mm} / \mathrm{hari}$. Untuk nilai curahan hujan efektif yang lain direkap pada Tabel 2.3

\begin{tabular}{|c|c|c|c|c|c|}
\hline \multirow{2}{*}{ Bulan } & \multirow{2}{*}{ Periode } & \multicolumn{2}{|c|}{ Hujan Andalan (mm) } & \multicolumn{2}{|c|}{ Hujan Efektif (mm/hari) } \\
\hline & & Padi $\left(\mathrm{R}_{80}\right)$ & Palawija $\left(\mathrm{R}_{50}\right)$ & Padi & Palawija \\
\hline \multirow{2}{*}{ Januari } & $\mathrm{I}$ & 58,00 & 97,00 & 2,707 & 4,527 \\
\hline & II & 74,00 & 150,00 & 3,238 & 6,563 \\
\hline \multirow{2}{*}{ Februari } & $\mathrm{I}$ & 46,00 & 79,00 & 2,147 & 3,687 \\
\hline & II & 45,00 & 93,00 & 2,423 & 5,008 \\
\hline \multirow{2}{*}{ Maret } & $\mathrm{I}$ & 58,00 & 93,00 & 2,707 & 4,340 \\
\hline & II & 49,00 & 122,00 & 2,144 & 5,338 \\
\hline \multirow{2}{*}{ April } & $\mathrm{I}$ & 58,50 & 149,00 & 2,730 & 6,953 \\
\hline & II & 50,00 & 148,00 & 2,333 & 6,907 \\
\hline \multirow{2}{*}{ Mei } & $\mathrm{I}$ & 40,00 & 90,00 & 1,867 & 4,200 \\
\hline & II & 47,00 & 64,00 & 2,056 & 2,800 \\
\hline \multirow{2}{*}{ Juni } & $\mathrm{I}$ & 27,00 & 60,00 & 1,260 & 2,800 \\
\hline & $\mathrm{II}$ & 10,00 & 53,50 & 0,467 & 2,497 \\
\hline \multirow{2}{*}{ Juli } & $\mathrm{I}$ & 30,00 & 82,00 & 1,400 & 3,827 \\
\hline & II & 27,00 & 55,00 & 1,181 & 2,406 \\
\hline \multirow{2}{*}{ Agustus } & $\mathrm{I}$ & 12,00 & 55,00 & 0,560 & 2,567 \\
\hline & II & 25,00 & 58,50 & 1,094 & 2,559 \\
\hline \multirow{2}{*}{ September } & $\mathrm{I}$ & 37,00 & 70,00 & 1,727 & 3,267 \\
\hline & II & 37,00 & 83,00 & 1,727 & 3,873 \\
\hline \multirow{2}{*}{ Oktober } & I & 37,00 & 91,00 & 1,727 & 4,247 \\
\hline & II & 36,00 & 85,00 & 1,575 & 3,719 \\
\hline \multirow{2}{*}{ Nopember } & $\mathrm{I}$ & 46,00 & 120,00 & 2,147 & 5,600 \\
\hline & II & 75,00 & 187,80 & 3,500 & 8,764 \\
\hline \multirow{2}{*}{ Desember } & $\mathrm{I}$ & 38,00 & 113,00 & 1,773 & 5,273 \\
\hline & II & 87,00 & 117,00 & 3,806 & 5,119 \\
\hline
\end{tabular}

Tabel 2.3. Curahan Hujan Efektif Untuk Padi dan Palawija

\subsection{Evapotranspirasi Potensial}

Evapotranspirasi potensial adalah nilai yang menggambarkan kebutuhan lingkungan, sekumpulan, atau kawasan pertanian untuk melakukan evapotranspirasi yang ditentukan oleh beberapa faktor, seperti intensitas penyinaran matahari, kecepatan angin, temperatur udara, dan tekanan udara. Evapotranspirasi potensial juga menggambarkan energi yang didapatkan dari matahari.

$$
E T_{0}=c\left[W R_{n}+(1-W) f(u)(e a-e d)\right]
$$

dimana: $E T_{0}=$ Evapotranspirasi Potensial (mm/hari); $c=$ Faktor koreksi akibat keadaan iklim siang / malam; $W=$ Faktor bobot; $R_{n}=$ Radiasi penyinaran matahari $(\mathrm{mm} / \mathrm{hari}) ;(1-W)=$ Faktor berat sebagai pengaruh angin dan kelembaban pada $E T_{0} ; f(u)=$ Fungsi kecepatan angin pada $E T_{0}$; (ea ed) = Perbedaan tekanan uap air jenuh dengan tekanan uap air nyata (mbar). Berdasarkan data yang telah didapat, maka pada bulan Januari: $E T_{0}=1,087[0,745 \times 6,027+(0,255)(0,343)(1,034)]=4,979$ $\mathrm{mm} /$ hari. Untuk perhitungan bulan yang lain direkapitulasi pada Tabel 2.4.

\section{4 | JURNAL REKAYASA SIPIL}


Tabel 2.4. Rekapitulasi Komponen Perhitungan Evapotranspirasi Potensial

\begin{tabular}{|c|c|c|c|c|c|c|c|c|c|c|c|c|c|c|}
\hline No Komponen & Simbol & Satuan & \multicolumn{12}{|c|}{ Bulan } \\
\hline 2 Tekanan Uap Nyata & ed & mbar & 31,866 & 32,334 & 35,747 & 35,748 & 35,801 & 35,622 & 35,812 & 35,016 & 34,155 & 33,527 & 34,688 & 35,028 \\
\hline 3 Perbedaan Tek. Uap & ea-ed & mbar & 1,034 & 0,886 & 1,053 & 1,192 & 0,969 & 0,978 & 0,998 & 1,354 & 1,125 & 2,573 & 1,442 & 1,252 \\
\hline 5 Faktor pengaruh angin \& kelembaban & $1-W$ & & 0,255 & 0,228 & 0,234 & 0,235 & 0,234 & 0,233 & 0,234 & 0,231 & 0,229 & 0,229 & 0,229 & 0,230 \\
\hline 6 Radiasi extra terrestial & $R_{a}$ & $\mathrm{~mm} / \mathrm{hari}$ & 15,016 & 15,511 & 15,700 & 15,290 & 14,384 & 13,879 & 14,079 & 14,784 & 15,295 & 15,405 & 15,111 & 14,816 \\
\hline 7 Radiasi Gel. Pendek & $R_{\mathrm{s}}$ & $\mathrm{mm} / \mathrm{hari}$ & 8,784 & 9,074 & 9,185 & 8,944 & 8,415 & 8,119 & 8,236 & 8,649 & 8,947 & 9,012 & 8,840 & 8,667 \\
\hline 10 Fungsi penyinaran & $f(n / N)$ & & 0,387 & 0,353 & 0,390 & 0,357 & 0,424 & 0,394 & 0,316 & 0,342 & 0,286 & 0,280 & 0,274 & 0,298 \\
\hline 11 Fungsi suhu & $f(t)$ & & 15,808 & 16,089 & 16,209 & 16,230 & 16,205 & 16,178 & 16,210 & 16,144 & 16,098 & 16,103 & 16,108 & 16,130 \\
\hline 12 Radiasi netto Gel. Panjang & $R_{n 1}$ & $\mathrm{~mm} / \mathrm{hari}$ & 0,561 & 0,511 & 0,487 & 0,446 & 0,527 & 0,493 & 0,393 & 0,440 & 0,382 & 0,384 & 0,357 & 0,382 \\
\hline 13 Radiasi netto & $R_{n}$ & $\mathrm{~mm} / \mathrm{hari}$ & 6,027 & 6,295 & 6,402 & 6,262 & 5,784 & 5,596 & 5,784 & 6,046 & 6,329 & 6,375 & 6,272 & $\overline{6,118}$ \\
\hline 14 Faktor Pembobot $R n$ & $W$ & & 0,745 & 0,772 & 0,766 & 0,765 & 0,766 & 0,767 & 0,766 & 0,769 & 0,771 & 0,771 & 0,771 & 0,770 \\
\hline 15 Faktor koreksi & $\begin{array}{c} \\
\end{array}$ & & 1,087 & 1,092 & 1,094 & 1,090 & 1,082 & 1,077 & 1,078 & 1,085 & 1,089 & 1,090 & 1,087 & 1,085 \\
\hline
\end{tabular}

\subsection{Debit andalan periode 15 harian}

Debit andalan 15-harian memunyai tingkat keandalan sebesar $80 \%$, yaitu debit dengan peluang kejadian $80 \%$ terpenuhi. Perhitungan debit andalan menggunakan Metode Ranking dengan mengurutkan data debit dari urutan terbesar ke terkecil sampai $n$-tahun. Dari urutan data debit dapat diketahui posisi $Q_{80}$ yang dapat dihitung dengan rumus (PU-1986):

$$
m=0,8 n+1
$$

dimana: $m=$ nomor urut data dari besar ke kecil; $n=$ jumlah data tahun pengamatan. Contoh untuk Januari I, diketahui jumlah tahun pengamatan $n=20$, sehingga: $m=0,8 n+1=0,8(20)+1=17$. Maka $Q_{80}$ berada di urutan $m=17$, Maka $Q_{80}=1,57 \mathrm{~m}^{3} / \mathrm{s}$. Untuk periode-periode yang lain dapat dilihat pada Tabel 2.5

Tabel 2.5. Hasil perhitugan Debit Andalan periode 15-harian $\left(\mathrm{m}^{3} / \mathrm{s}\right)$

\begin{tabular}{|c|c|c|c|c|c|c|c|c|c|c|c|c|c|c|c|c|c|c|c|c|c|c|c|c|}
\hline \multirow{2}{*}{$\begin{array}{l}\text { Bulan } \\
\text { Periode }\end{array}$} & \multicolumn{3}{|c|}{ Jan } & Feb & \multicolumn{2}{|r|}{ Mar } & \multicolumn{2}{|r|}{ Apr } & \multicolumn{2}{|r|}{ Mei } & \multicolumn{2}{|r|}{ Jun } & \multicolumn{2}{|r|}{ Jul } & \multicolumn{2}{|r|}{ Agus } & \multicolumn{2}{|r|}{ Sep } & \multicolumn{2}{|r|}{ Okt } & \multicolumn{2}{|r|}{ Nop } & \multicolumn{2}{|r|}{ Des } \\
\hline & I & II & I & II & I & II & I & II & I & II & I & II & I & II & I & II & I & II & I & II & I & II & I & II \\
\hline 1 & 14,55 & 9,64 & 11,36 & 16,22 & 8,59 & 9,39 & 15,28 & 20,65 & 16,09 & 13,89 & 8,27 & 9,16 & 11,55 & 14,23 & 10,27 & 8,54 & 8,95 & 8,25 & 9,02 & 12,43 & 12,77 & 14,68 & 13,61 & 15,14 \\
\hline 3 & 8,44 & 9,12 & 8,59 & 6,94 & 7,82 & 8,47 & 12,21 & 10,37 & 8,78 & 8,75 & 6,52 & 6,44 & 6,86 & 4,76 & 4,71 & 6,79 & 5,98 & 5,82 & 6,61 & 10,62 & 9,45 & 12,75 & 14,14 & 14,91 \\
\hline 4 & 7,44 & 6,79 & 7,17 & 6,94 & 6,41 & 7,45 & 7,34 & 10,06 & 8,78 & 7,26 & 5,95 & 3,84 & 4,61 & 2,73 & 3,79 & 4,49 & 5,92 & 5,73 & 6,03 & 10,60 & 8,10 & 9,93 & 14,14 & 14,65 \\
\hline 5 & 7,02 & 6,13 & 6,10 & 6,94 & 5,65 & 6,97 & 7,28 & 10,06 & 8,12 & 5,52 & 3,00 & 2,77 & 3,72 & 2,19 & 2,28 & 4,36 & 4,77 & 5,06 & 4,87 & 6,91 & 6,53 & 9,73 & 13,61 & 9,74 \\
\hline 6 & 6,29 & 5,53 & 5,66 & 5,58 & 4,94 & 6,46 & 7,13 & 9,84 & 7,64 & 5,42 & 2,79 & 2,73 & 3,18 & 2,08 & 2,16 & 4,11 & 2,82 & 3,22 & 4,87 & 6,62 & 5,44 & 8,26 & 6,86 & 7,94 \\
\hline 9 & 4,28 & 3,64 & 4,08 & 3,55 & 3,49 & 5,50 & 6,50 & 5,11 & 4,63 & 2,89 & 2,21 & 2,24 & 1,96 & 1,61 & 1,42 & 2,11 & 2,28 & 2,45 & 2,80 & 4,81 & 3,29 & 3,72 & 3,85 & 6,18 \\
\hline 10 & 4,00 & 3,47 & 2,91 & 3,39 & 3,04 & 5,37 & 5,03 & 4,37 & 3,07 & 2,47 & 2,03 & 1,80 & 1,71 & 1,49 & 1,41 & 1,85 & 1,99 & 2,04 & 2,60 & 4,36 & 3,27 & 3,52 & 2,99 & 4,57 \\
\hline 11 & 3,36 & 3,34 & 2,56 & 3,29 & 2,69 & 3,43 & 4,94 & 4,32 & 3,03 & 2,28 & 1,88 & 1,80 & 1,55 & 1,43 & 1,22 & 1,82 & 1,93 & 2,04 & 2,12 & 2,11 & 3,27 & 2,84 & 2,86 & 3,49 \\
\hline 12 & 3,00 & 3,05 & 2,47 & 3,22 & 2,29 & 2,78 & 4,94 & 3,84 & 2,57 & 2,25 & 1,74 & 1,72 & 1,46 & 1,31 & 1,19 & 1,64 & 1,79 & 1,96 & 2,08 & 2,04 & 2,97 & 2,72 & 2,54 & 2,85 \\
\hline 13 & 2,97 & 3,00 & 2,37 & 1,73 & 2,13 & 2,32 & 2,25 & 3,38 & 2,40 & 2,15 & 1,71 & 1,56 & 1,41 & 1,31 & 1,10 & 1,51 & 1,57 & 1,52 & 2,03 & 1,94 & 2,70 & 2,25 & 2,32 & 2,82 \\
\hline 14 & 2,87 & 2,28 & 2,35 & 1,71 & 1,96 & 1,76 & 2,16 & 3,09 & 2,38 & 1,86 & 1,52 & 1,29 & 1,38 & 1,29 & 1,08 & 1,20 & 1,39 & 1,42 & 1,78 & 1,94 & 2,26 & 2,17 & 2,20 & 2,55 \\
\hline 19 & 0,76 & 1,32 & 1,38 & 1,19 & 1,32 & 1,06 & 0,93 & 1,71 & 1,11 & 0,99 & 1,05 & 0,76 & 0,88 & 0,82 & 0,63 & 0,49 & 0,61 & 0,84 & 1,05 & 0,77 & 0,95 & 0,93 & 0,96 & 1,17 \\
\hline 20 & 0,55 & 1,29 & 1,29 & 1,16 & 1,29 & 0,63 & 0,81 & 0,62 & 0,90 & 0,97 & 1,03 & 0,65 & 0,87 & 0,74 & 0,57 & 0,44 & 0,48 & 0,70 & 1,01 & 0,51 & 0,71 & 0,83 & 0,76 & 0,86 \\
\hline Jlh date & 20 & 20 & 20 & 20 & 20 & 20 & 20 & 20 & 20 & 20 & 20 & 20 & 20 & 20 & 20 & 20 & 20 & 20 & 20 & 20 & 20 & 20 & 20 & 20 \\
\hline $\begin{array}{l}\text { Urutan } \\
\end{array}$ & 17 & 17 & 17 & 17 & 17 & 17 & 17 & 17 & 17 & 17 & 17 & 17 & 17 & 17 & 17 & 17 & 17 & 17 & 17 & 17 & 17 & 17 & 17 & 17 \\
\hline $\mathrm{Q}_{80}$ & 1,57 & 1,75 & 2,18 & 1,34 & 1,67 & 1,50 & 1,34 & 2,40 & 1,74 & 1,47 & 1,14 & 0,99 & 1,09 & 1,19 & 0,70 & 1,04 & 1,10 & 1,12 & 1,45 & 1,02 & 1,37 & 1,57 & 1,15 & 1,36 \\
\hline
\end{tabular}

\subsection{Menentukan awal musim tanam}

Setelah mendapatkan debit andalan, kemudian dicari volume andalannya selama $24 \mathrm{jam}$. Sebagai contoh untuk periode Januari I diperoleh: $Q_{80}=1,57 \mathrm{~m}^{3} / \mathrm{s}$ (diperoleh dari Tabel 2.5) dan $t=86400 \mathrm{~s}$ (jumlah detik dalam 1 hari). Jadi, volume andalan dalam 1 hari adalah

VOLUME 12 NO. 1, FEBRUARI 2016 | 5 


$$
V_{80}=Q_{80} t=1,5(86400)=135475 \mathrm{~m}^{3}
$$

Untuk menentukan volume andalan $V_{80}$ dan ranking volume andalan dapat dilihat pada Tabel 2.6. Berdasarkan Tabel 2.6, maka untuk awal musim tanam dipilih Januari I (1 $\left.188241 \mathrm{~m}^{3}\right)$, karena Januari I mendapatkan ranking terbesar kedua setelah Januari II (1 $\left.203392 \mathrm{~m}^{3}\right)$.

Tabel 2.6. Perhitungan komulatif volume andalan sungai dan rangking awal musim tanam

\begin{tabular}{|c|c|c|c|c|c|c|c|c|c|c|c|c|c|c|}
\hline \multirow{2}{*}{$\frac{\bar{\Xi}}{\vec{\Xi}}$} & \multirow{2}{*}{$\begin{array}{l}\frac{\pi}{0} \\
0 \\
0 \\
0\end{array}$} & \multirow{2}{*}{ 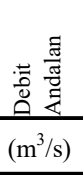 } & \multirow{2}{*}{ 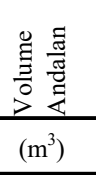 } & \multicolumn{9}{|c|}{ Kumulatif per musim tanam } & \multirow{2}{*}{ 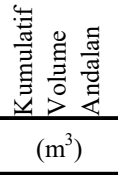 } & \multirow{2}{*}{$\frac{\stackrel{b}{\Xi}}{\stackrel{\Xi}{E}}$} \\
\hline & & & & & & & & $\left(\mathrm{m}^{3}\right)$ & & & & & & \\
\hline \multirow{2}{*}{ Jan } & I & 1,57 & 135475 & 135475 & & & & & & & & & & \\
\hline & II & 1,75 & 151524 & 286999 & 151524 & & & & & & & & & \\
\hline \multirow{2}{*}{ Peb } & $\mathrm{I}$ & 2,18 & 188529 & 475528 & 340053 & 188529 & & & & & & & & \\
\hline & II & 1,34 & 115643 & 591172 & 455696 & 304172 & 115643 & & & & & & & \\
\hline \multirow{2}{*}{ Mart } & $\mathrm{I}$ & 1,67 & 144230 & 735402 & 599927 & 448403 & 259873 & 144230 & & & & & & \\
\hline & II & 1,50 & 129384 & 864786 & 729311 & 577787 & 389257 & 273614 & 129384 & & & & & \\
\hline \multirow{2}{*}{ Apr } & $\mathrm{I}$ & 1,34 & 115791 & 980576 & 845101 & 693577 & 505048 & 389405 & 245175 & 115791 & & & & \\
\hline & II & 2,40 & 207664 & 1188241 & 1052765 & 901241 & 712712 & 597069 & 452839 & 323455 & 207664 & & 1.188 .241 & 2 \\
\hline \multirow{2}{*}{ Mei } & $\mathrm{I}$ & 1,74 & 150627 & & 1203392 & 1051868 & 863339 & 747696 & 603466 & 474082 & 358291 & 150627 & 1.203 .392 & 1 \\
\hline & II & 1,47 & 127117 & 127117 & & 1178986 & 990456 & 874813 & 730583 & 601199 & 485408 & 277744 & 1.178.986 & 3 \\
\hline \multirow{2}{*}{ Juni } & $\mathrm{I}$ & 1,14 & 98267 & 225384 & 98267 & & 1088723 & 973080 & 828850 & 699466 & 583675 & 376011 & 1.088 .723 & 5 \\
\hline & II & 0,99 & 85463 & 310847 & 183730 & 85463 & & 1058543 & 914313 & 784929 & 669139 & 461474 & 1.058 .543 & 9 \\
\hline \multirow{2}{*}{ Juli } & I & 1,09 & 93888 & 404735 & 277618 & 179351 & 93888 & & 1008201 & 878817 & 763027 & 555362 & 1.008.201 & 11 \\
\hline & II & 1,19 & 102924 & 507659 & 380542 & 282275 & 196812 & 102924 & & 981741 & 865951 & 658286 & 981.741 & 12 \\
\hline \multirow{2}{*}{ Agust- } & $\mathrm{I}$ & 0,70 & 60644 & 568304 & 441187 & 342920 & 257456 & 163568 & 60644 & & 926595 & 718931 & 926.595 & 14 \\
\hline & II & 1,04 & 89964 & 658268 & 531151 & 432884 & 347420 & 253532 & 150608 & 89964 & & 808895 & 808.895 & 19 \\
\hline \multirow{2}{*}{ Sep } & $\mathrm{I}$ & 1,10 & 94810 & 753078 & 625960 & 527693 & 442230 & 348342 & 245418 & 184774 & 94810 & & 753.078 & 21 \\
\hline & II & 1,12 & 96925 & & 722885 & 624618 & 539155 & 445267 & 342343 & 281698 & 191734 & 96925 & 722.885 & 24 \\
\hline \multirow{2}{*}{ Okt } & $\mathrm{I}$ & 1,45 & 124934 & 124934 & & 749553 & 664089 & 570201 & 467277 & 406633 & 316669 & 221859 & 749.553 & 23 \\
\hline & II & 1,02 & 87760 & 212695 & 87760 & & 751850 & 657962 & 555038 & 494393 & 404429 & 309620 & 751.850 & 22 \\
\hline \multirow{2}{*}{ Nop } & $\mathrm{I}$ & 1,37 & 118598 & 331293 & 206359 & 118598 & & 776560 & 673636 & 612992 & 523028 & 428218 & 776.560 & 20 \\
\hline & II & 1,57 & 135360 & 466653 & 341719 & 253958 & 135360 & & 808996 & 748352 & 658388 & 563578 & 808.996 & 18 \\
\hline \multirow{2}{*}{ Des } & $\mathrm{I}$ & 1,15 & 99260 & 565913 & 440979 & 353218 & 234620 & 99260 & & 847612 & 757648 & 662838 & 847.612 & 17 \\
\hline & II & 1,36 & 117763 & 683676 & 558742 & 470981 & 352383 & 217023 & 117763 & & 875411 & 780601 & 875.411 & 16 \\
\hline \multirow{2}{*}{ Jan } & $\mathrm{I}$ & 1,57 & 135475 & 819152 & 694217 & 606457 & 487858 & 352498 & 253238 & & & 916076 & 916.076 & 15 \\
\hline & II & 1,75 & 151524 & 970676 & 845741 & 757981 & 639382 & 504022 & 404762 & & & & 970.676 & 13 \\
\hline \multirow{2}{*}{ Peb } & $\mathrm{I}$ & 2,18 & 188529 & & 1034270 & 946510 & 827912 & 692552 & 593292 & & & & 1.034 .270 & 10 \\
\hline & II & 1,34 & 115643 & & & 1062153 & 943555 & 808195 & 708935 & & & & 1.062.153 & 8 \\
\hline \multirow{2}{*}{ Mart } & $\mathrm{I}$ & 1,67 & 144230 & & & & 1087785 & 952425 & 853165 & & & & 1.087 .785 & 6 \\
\hline & II & 1,50 & 129384 & & & & & 1081809 & 982549 & & & & 1.081 .809 & 7 \\
\hline \multirow{2}{*}{ Apr } & $\mathrm{I}$ & 1,34 & 115791 & & & & & & 1098340 & & & & 1.098.340 & 4 \\
\hline & II & 2,40 & 207664 & & & & & & & & & & & \\
\hline
\end{tabular}

\subsection{Rekapitulasi kebutuhan air}

Dalam mencari besarnya kebutuhan air untuk irigasi tanaman, dilakukan perhitungan kebutuhan air yang dipengaruhi oleh faktor-faktor yang telah dibahas sebelumnya. Berikut contoh perhitungan kebutuhan irigasi untuk pola tanam padi-padi-padi dengan awal tanam Januari II yang dapat dilihat pada Tabel 2.7.

\section{I JURNAL REKAYASA SIPIL}


Tabel 2.7. Perhitungan kebutuhan air Daerah Irigasi Batang Lampasi pola tanam: Padi-Padi-Padi awal tanam Januari II

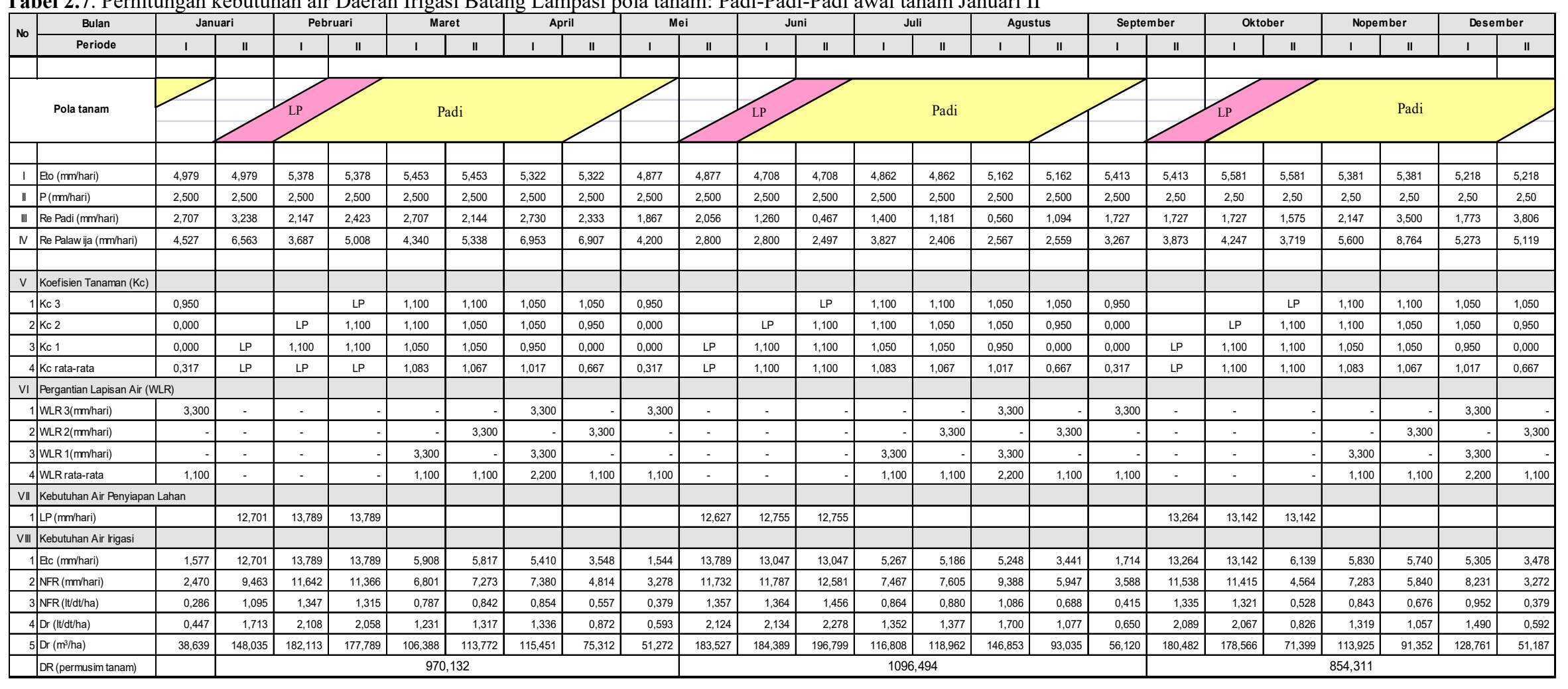


Untuk kebutuhan air yang lain dapat dilihat pada Tabel 2.8. berikut :

Tabel 2.8. Rekapitulasi kebutuhan air irigasi

\begin{tabular}{|c|c|c|c|c|c|}
\hline \multirow{2}{*}{ No } & \multirow{2}{*}{ Pola Tanam } & \multirow{2}{*}{ Awal Tanam } & \multirow{2}{*}{$\begin{array}{l}\text { Musim } \\
\text { Tanam }\end{array}$} & \multicolumn{2}{|c|}{ Kebutuhan Air Irigasi $\left(\mathrm{m}^{3} / \mathrm{ha}\right)$} \\
\hline & & & & Padi & Palawija \\
\hline \multirow{6}{*}{1} & \multirow{6}{*}{ Padi - Padi } & \multirow{3}{*}{$\begin{array}{c}\text { Januari I } \\
\text { (Eksisting) }\end{array}$} & I & 952,901 & - \\
\hline & & & II & 1081,264 & - \\
\hline & & & III & - & - \\
\hline & & \multirow{3}{*}{ Januari II } & I & 970,132 & - \\
\hline & & & II & 1069,167 & - \\
\hline & & & III & - & - \\
\hline \multirow{6}{*}{2} & \multirow{6}{*}{ Padi - Padi - Padi } & \multirow{3}{*}{ Januari I } & I & 942,993 & - \\
\hline & & & II & 1056,347 & - \\
\hline & & & III & 988,267 & - \\
\hline & & \multirow{3}{*}{ Januari II } & $\mathrm{I}$ & 970,132 & - \\
\hline & & & II & 1096,494 & - \\
\hline & & & III & 854,311 & - \\
\hline \multirow{6}{*}{3} & \multirow{6}{*}{ Padi - Padi - Palawija } & \multirow{3}{*}{ Januari I } & I & 952,901 & - \\
\hline & & & II & 1055,923 & - \\
\hline & & & III & - & 169,795 \\
\hline & & \multirow{3}{*}{ Januari II } & I & 912,553 & - \\
\hline & & & II & 887,667 & - \\
\hline & & & III & - & 195,011 \\
\hline
\end{tabular}

\subsection{Optimasi pemakaian air dan lahan}

Model optimasi yang digunakan adalah goal programming. Model optimasi ini memunyai fungsi sasaran/tujuan adalah memaksimalkan luas lahan; dan meminimalkan kebutuhan air, dan fungsi kendala adalah luas areal irigasi dan volume andalan sungai. Luas Daerah Irigasi Batang Lampasi yang difungsikan sebesar 1500 ha, sedangkan volume andalan sungai dapat dilihat pada Tabel 2.9 (yang disarikan dari Tabel 2.6) berikut:

Tabel 2.9. Rekapitulasi Volume Andalan Sungai

\begin{tabular}{crr}
\hline \multirow{2}{*}{ Musim Tanam } & \multicolumn{2}{c}{ Volume Andalan $\left(\mathrm{m}^{3}\right)$} \\
\cline { 2 - 3 } & \multicolumn{1}{c}{ Januari I } & \multicolumn{1}{c}{ Januari II } \\
\hline \hline I & 1.188 .241 & 1.203 .392 \\
\hline II & 808.895 & 753.078 \\
\hline III & 875.411 & 916.076 \\
\hline
\end{tabular}

Penentuan solusi optimal menggunakan metode simpleks didasarkan pada teknik eleminasi Gauss Jordan. Penentuan solusi optimal dilakukan dengan memeriksa titik ekstrim satu per satu dengan cara perhitungan iteratif dan dilakukan tahap demi tahap yang disebut dengan iterasi. Berikut contoh tabel simpleks awal pada pola tanam padi-padi-padi dengan awal tanam Januari II pada Tabel 2.10 . 
Tabel 2.10. Simpleks Awal untuk pola tanam Padi- Padi- Padi pada Januari II

\begin{tabular}{|c|c|c|c|c|c|c|c|c|c|c|c|c|c|c|c|c|c|c|c|c|c|}
\hline Basic & $\begin{array}{l}C_{j} \\
\text { Variable }\end{array}$ & $\begin{array}{c}0 \\
X_{1 a} \\
\end{array}$ & $\begin{array}{c}0 \\
X_{1 b} \\
\end{array}$ & $\begin{array}{c}0 \\
X_{2 \mathrm{a}} \\
\end{array}$ & $\begin{array}{c}0 \\
X_{2 b} \\
\end{array}$ & $\begin{array}{r}0 \\
X_{3 a} \\
\end{array}$ & $\begin{array}{c}0 \\
X_{3 b} \\
\end{array}$ & $\begin{array}{c}0 \\
d_{1}^{-}\end{array}$ & $\begin{array}{c}0 \\
d_{2}^{-}\end{array}$ & $\begin{array}{c}0 \\
d_{3}^{-}\end{array}$ & $\begin{array}{r}P_{2} \\
d_{4}\end{array}$ & $\begin{array}{r}P_{2} \\
d_{5}{ }^{-} \\
\end{array}$ & $\begin{array}{c}P_{2} \\
d_{6}{ }^{-}\end{array}$ & $\begin{array}{l}P_{1} \\
d_{1}^{+}\end{array}$ & $\begin{array}{c}P_{1} \\
d_{2}{ }^{+}\end{array}$ & $\begin{array}{c}P_{1} \\
d_{3}{ }^{+}\end{array}$ & $\begin{array}{c}P_{2} \\
d_{4}{ }^{+} \\
\end{array}$ & $\begin{array}{c}P_{2} \\
d_{5}{ }^{+}\end{array}$ & $\begin{array}{c}P_{2} \\
d_{6}{ }^{+}\end{array}$ & RHS & Rasio \\
\hline 0 & $d_{2}^{-}$ & 0 & 0 & 1 & 0 & 0 & 0 & 0 & 1 & 0 & 0 & 0 & 0 & 0 & -1 & 0 & 0 & 0 & 0 & 1500 & 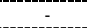 \\
\hline$P_{2}$ & $d_{4}^{-}$ & 0 & 970 & 0 & 0 & 0 & 0 & 0 & 0 & 0 & 1 & 0 & 0 & 0 & 0 & 0 & -1 & 0 & 0 & 1203392 & 1240,442 \\
\hline$P_{2}$ & $d_{5}$ & 0 & 0 & 0 & 1069 & 0 & 0 & 0 & 0 & 0 & 0 & 1 & 0 & 0 & 0 & 0 & 0 & -1 & 0 & 753078 & 704,359 \\
\hline$P_{2}$ & $d_{6}^{-}$ & 0 & 0 & 0 & 0 & 0 & 0 & 0 & 0 & 0 & 0 & 0 & 1 & 0 & 0 & 0 & 0 & 0 & -1 & 0 & \\
\hline$P_{2}$ & $Z_{j}$ & 0 & 0 & 0 & 1069 & 0 & 0 & 0 & 0 & 0 & 1 & 1 & 1 & 0 & 0 & 0 & -1 & -1 & -1 & 1956470 & \\
\hline$P_{1}$ & $C_{j}-Z_{j}$ & 0 & 0 & 0 & 0 & 0 & 0 & 0 & 0 & 0 & 0 & 0 & 0 & 1 & 1 & 1 & 0 & 0 & 0 & & \\
\hline
\end{tabular}

Tabel simpleks awal menunjukkan bahwa variable $X_{1 a}$ akan masuk basis $d_{4}^{-}$. Selanjutnya, dengan mengaplikasikan prosedur simpleks akan diperoleh solusi yang optimal seperti pada Tabel 2.11 berikut:

Tabel 2.11. Hasil Optimasi Untuk Pola Tanam Padi-Padi-Padi

\begin{tabular}{|c|c|c|c|c|c|c|c|c|c|c|c|c|c|c|c|c|c|c|c|c|}
\hline Basic & ariable & $\begin{array}{c}0 \\
X_{1 a}\end{array}$ & $\begin{array}{c}0 \\
X_{1 b}\end{array}$ & $\begin{array}{c}0 \\
X_{2 a}\end{array}$ & $\begin{array}{c}0 \\
X_{2 b}\end{array}$ & $\begin{array}{c}0 \\
X_{3 a}\end{array}$ & $\begin{array}{c}0 \\
X_{3 b}\end{array}$ & $\begin{array}{c}0 \\
d_{1}^{-}\end{array}$ & $\begin{array}{c}0 \\
d_{2}^{-}\end{array}$ & $\begin{array}{c}0 \\
d_{3}^{-}\end{array}$ & $\begin{array}{c}P_{2} \\
d_{4}^{-}\end{array}$ & $\begin{array}{c}P_{2} \\
d_{5}{ }^{-}\end{array}$ & $\begin{array}{c}P_{2} \\
d_{6}{ }^{-}\end{array}$ & $\begin{array}{c}P_{1} \\
d_{1}^{+}\end{array}$ & $\begin{array}{c}P_{1} \\
d_{2}^{+}\end{array}$ & $\begin{array}{l}P_{1} \\
d_{3}{ }^{+}\end{array}$ & $\begin{array}{c}P_{2} \\
d_{4}{ }^{+}\end{array}$ & $\begin{array}{c}P_{2} \\
d_{5}{ }^{+}\end{array}$ & $\begin{array}{c}P_{2} \\
d_{6}^{+}\end{array}$ & RHS \\
\hline o & $d_{1}^{-}$ & 0 & 0 & 0 & 0 & 0 & 0 & 1 & 0 & 0 & 0 & 0 & 0 & -1 & 0 & 0 & 0 & 0 & 0 & 239,927 \\
\hline 0 & $d_{3}^{-}$ & 0 & 0 & 0 & 0 & 1 & 0 & 0 & 0 & 1 & 0 & 0 & 0 & 0 & 0 & -1 & 0 & 0 & 0 & 614,196 \\
\hline$P_{2}$ & $\mathrm{~d}_{4}^{-}$ & 1 & 0 & 0 & 0 & 0 & 0 & 0 & 0 & 0 & 0 & 0 & 0 & 0 & 0 & 0 & 0 & 0 & 0 & 1260,073 \\
\hline
\end{tabular}

Rekapitulasi hasil perhitungan tabel simpleks yang lain dapat dilihat pada Tabel 2.12 berikut:

Tabel 2.12. Rekapitulasi Luas Tanam Optimum dengan Tabel Simpleks

\begin{tabular}{|c|c|c|c|c|c|}
\hline \multirow{2}{*}{ Awal Tanam } & \multirow{2}{*}{ Musim Tanam } & \multirow{2}{*}{ Jenis Tanaman } & \multicolumn{3}{|c|}{ Pola tanam } \\
\hline & & & I & II & III \\
\hline \multirow{6}{*}{ Januari I } & \multirow{2}{*}{ I } & Padi (Ha) & 1247 & 1260 & 1247 \\
\hline & & Palawija (Ha) & - & - & - \\
\hline & \multirow{2}{*}{ II } & Padi (Ha) & 748 & 766 & 766 \\
\hline & & Palawija (Ha) & - & - & \\
\hline & \multirow{2}{*}{ III } & Padi (Ha) & & 886 & - \\
\hline & & Palawija (Ha) & & - & 1500 \\
\hline \multirow{6}{*}{ Januari II } & \multirow{2}{*}{ I } & Padi (H) & 1240 & 1240 & 1319 \\
\hline & & Palawija (Ha) & - & - & - \\
\hline & \multirow{2}{*}{ II } & Padi (Ha) & 704 & 687 & 848 \\
\hline & & Palawija (Ha) & - & - & - \\
\hline & \multirow{2}{*}{ III } & Padi (Ha) & & 1072 & \\
\hline & & Palawija (Ha) & & - & 1500 \\
\hline & & & -Padi & Padi-Padi-Padi & lawija \\
\hline
\end{tabular}

\section{KESIMPULAN}

Berdasarkan hasil pengukuran debit sesaat, efisiensi saluran primer, sekunder dan tersier di Daerah Irigasi Batang Lampasi diperkirakan sebesar $64 \%$. Volume andalan terbesar adalah Januari II sebesar $1203392 \mathrm{~m}^{3}$ dan Januari I sebesar $1188241 \mathrm{~m}^{3}$, sehingga keduanya dipakai sebagai awal musim tanam. Optimasi pemakaian air dan lahan menggunakan metode goal programming, dengan fungsi sasarannya adalah memaksimalkan luas lahan dan meminimalkan kebutuhan air, fungsi kendalanya yaitu luas areal irigasi sebesar $1500 \mathrm{Ha}$, volume andalan sungai, dan tiga alternatif pola tanam (padi-padi sebagai kondisi eksisting, padi-padi-padi, padi-padi-palawija) memberikan hasil 
yang optimum yaitu awal musim tanam pada Januari II dengan pola tanam padi (1319 ha) - padi (848 ha) - palawija (1500 ha).

\section{UCAPAN TERIMA KASIH}

Ucapan terima kasih penulis tujukan kepada Kepala Dinas PSDA Provinsi Sumatera Barat dan Kepala Balai PSDA Wilayah Bukittinggi yang telah membantu menyediakan data sekunder.

\section{DAFTAR KEPUSTAKAAN}

Agus, I., 2005, Irigasi dan Bangunan Irigasi. Jurusan Teknik Sipil, Politeknik Negeri Padang

Aji, P., 2009 Studi Optimasi Penggunaan Air pada Daerah Irigasi Mrican Kanan di Kabupaten Kediri, Jawa Timur, Tesis Teknik Sipil, ITS Surabaya

Mahmud, A., 2009, Optimasi Potensi dan Pola Pemanfaatan Air Irigasi, studi kasus pada D.I Wawatobi, Penerbit Universitas Muhammadiyah Kendari.

Pamuji, P., 2007, Melakukan Optimasi Pengelolaan Air Irigasi D.I. Banjaran Kabupaten Banyumas Jawa Tengah. Jurusan Teknik Sipil UNSOED Purwokerto.

PU, 1986, Standar Perencanaan Irigasi KP-01 Perencanaan. Direktorat Jenderal Pengairan, Departemen Pekerjaan Umum

Taufan, L., Mochammad, Nadjaji, A. dan Edijatno 2013, Studi Optimasi Pola Tanam Pada Daerah Irigasi Konto Kabupaten Jombang. Jurnal Teknik Pomits Jurusan Teknik Sipil Fakultas Teknik Sipil dan Perencanaan, Institut Teknologi Sepuluh Nopember Surabaya, Volume 2, No.1, pp. 1-6.

Talitha, J., 2013, Studi Optimasi Penggunaan Lahan dan Air D.I. Kandis Kecamatan Lengayang Kabupaten Pesisir Selatan. Tesis Magister Teknik Sipil Universitas Andalas Padang

Wahyudi, A., N. Anwar., dan Edijatno, 2014, Studi Optimasi Pola Tanam pada Daerah Irigasi Warujayeng Kertosono dengan Program Linier Kabupaten Nganjuk. Jurnal Teknik Sipil ITS, Volume. 3, (2014) No.1, pp. 30-35 ISSN: 2337-3539 (2301-9271 Print) 